\title{
pro.posıções
}

$e$-ISSN 1980-6248

http://dx.doi.org/10.1590/1980-6248-2016-0127

DIVERSO E PROSA

\section{Os jovens e a política: do mal-estar a novas formas de expressão na vida pública. Entrevista com Anne Muxel}

\section{Young people and politics: from malaise to new forms of expression in public life. Interview with Anne Muxel}

Kimi Tomizaki (i)

Marcelo Daniliauskas (ii)

\begin{abstract}
(i) Universidade de São Paulo - USP, São Paulo, SP, Brasil. kimi@usp.br
(ii) Doutor pela Universidade de São Paulo - USP, São Paulo, SP, Brasil. marcelo.daniliauskas@gmail.com
\end{abstract}

Anne Muxel é diretora de pesquisa em ciências políticas do Centre National de la Recherche Scientifique (CNRS), no Centre de Recherches Politiques de Sciences Po (CEVIPOF), no qual desenvolve pesquisas sobre atitudes e comportamentos políticos, com ênfase sobre as questões eleitorais e os fenômenos de socialização política e transmissão intergeracional. Ao longo de mais de 30 anos de pesquisa, produziu extensa e rica contribuição para a compreensão das relações entre os jovens e a política na França e em pesquisas comparadas com outros países europeus. Entre seus principais trabalhos, gostaríamos de destacar: Toi, moi et la politique. Amour et convictions (éditions du Seuil, octobre 2008); Les jeunes et les élections européennes : un paradoxe démocratique? (Delwit Pascal, Poirier Ph., Parlement puissant, électeurs absents? Les élections européennes, Editions de l'université de Bruxelles, 2005); Le vote de tous les refus. Les élections présidentielles et législatives de 2002 (Presses de Sciences Po, 2003); La participation politique des jeunes : soubresauts, fractures, ajustements (Revue Française de Science Politique, vol. 52, n 5-6, octobre-décembre 2002) ; L'expérience politique des jeunes (Presses de Sciences Po, 2001); Les jeunes d'Europe du Sud et la politique. Une enquête comparative France, Italie, Espagne (L'Harmattan, 2001 [codirection Marlaine Cacouault]). 


\section{pro.posıções}

$e$-ISSN 1980-6248

http://dx.doi.org/10.1590/1980-6248-2016-0127

Os trabalhos conduzidos por Anne Muxel são referências incontornáveis para todo pesquisador que pretenda discutir o desenvolvimento de comportamentos políticos, sobretudo entre jovens, bem como a transmissão, de uma geração a outra, de valores, práticas e percepções sobre o mundo da política, com ênfase sobre o ambiente familiar e a importância das relações de afeto que permeiam esses processos.

Esta entrevista é o resultado do início de uma interlocução que se deu em períodos diferentes, entre 2015 e 2016, por ocasião de duas temporadas de estudo e pesquisa dos entrevistadores em Paris (“doutorado-sanduíche” de Marcelo Daniliauskas e pósdoutoramento de Kimi Tomizaki), nos quais tivemos oportunidade de discutir nossas pesquisas e conduzir uma longa "conversa" com a autora, em dois tempos, cuja síntese apresentaremos em seguida. Os leitores encontrarão, nesta entrevista, um esforço de síntese em torno das principais contribuições de Muxel para os estudos sobre juventude e política, partindo de questões que, atualmente, são muito desafiadoras para os pesquisadores do tema no Brasil.

Entrevistadores: Gostaríamos de começar perguntando sobre sua trajetória intelectual: como você se aproximou de seus objetos de pesquisa, sobretudo as relações entre a juventude a política?

Muxel: Desde que me lembro, uma das questões fundamentais que me interessavam quando comecei a fazer sociologia era compreender o modo como se formavam as identidades políticas dos indivíduos. Como se forjavam os valores, as convicções, as opiniões que poderiam constituir a identidade profunda, as crenças e o sistema de valores dos indivíduos? É uma questão que me habita há muito tempo e, desde minha tese de doutorado, privilegio o papel da família para abordar a formação da identidade politica. A familia tem um papel importante na formação e transmissão de conviç̧ões políticas e religiosas. Para além disso, as famílias formam uma comunidade de experiências que encarna a própria essência da pluralidade democrática. Isso porque ela coloca em interação individualidades que vão, por vezes, partilhar uma mesma história, um mesmo conjunto de valores, mas que é também marcado por diferenças, oposiçoes, diferentes opiniões. Bem mais tarde, no meu livro Toi, moi et la politique: amour et convictions, retomei essa ideia da familia como terreno de experiência da aventura democrática, como laboratório da formação de identidades políticas. A família me interessa 


\section{pro.posições}

$e$-ISSN 1980-6248

porque ela exige uma abordagem transgeracional, portanto uma visão diacrônica dos fenômenos políticos. Ainda muito jovem, já em minha tese de doutorado, eu estudei a transmissão das escolhas e valores políticos entre três gerações - avós, pais e filhos. O campo de pesquisas sobre a socialização politica permite interrogar a maneira como as pessoas não somente exprimem opiniões, tomando parte nas decisões políticas e sendo ativas quanto à expressão de sua cidadania, mas também, mais amplamente, o modo como os indivíduos interpretam e dão sentido ao mundo ao seu redor e a seu lugar na sociedade. Todas essas questões, portanto, me interpelam fortemente faz. muito tempo.

O tempo da juventude, por sua vez, é um periodo da vida particularmente interessante para observar a construção das identidades políticas porque, em primeiro lugar, é um tempo de negociação entre as heranças, as primeiras aprendizagens oriundas da socialização primária, de tudo que foi transmitido pela família, e as experimentações, a vivência da autonomia, conduð̧indo à construção de escolhas pessoais, que intervêm no quadro da socialização secundária. O tempo da juventude é um periodo de tensão entre a herança familiar, mas também escolar, e a influência das pessoas novas com quem nos encontramos, grupos de amigos ou de trabalho, mas também relações amorosas e conjugais. Em seguida à defesa da minha tese, que foi consagrada ao que eu chamo de "socialização intencional familiar", sobre três gerações familiares, desenvolvi um projeto bastante ambicioso que consistia em seguir a entrada na política de uma mesma coorte de jovens entre 18 e 30 anos, durante um período de 12 anos, tendo em vista reinterrogá-los a cada grande eleição na França. Pude, assim, seguir seus itinerários de participação política e, portanto, conduzir um estudo longitudinal sobre o processo de sua socialização política a partir da participação desses jovens no exercício de seu papel como cidadãos ativos.

Então, essas eram as questões que estavam na origem da minha trajetória como pesquisadora e fundaram os campos de pesquisa aos quais me dediquei, de uma maneira ou de outra, por meio de abordagens tanto qualitativas quanto quantitativas. Eu continuo a trabalhar hoje sobre essas questões, desenvolvendo notadamente a temática "política, afetividade, intimidade" e lançando mão de várias disciplinas, não somente a sociologia e as ciências politicas, que são minhas disciplinas de pertencimento, mas também a história, a filosofia, a antropologia, a psicanálise e mesmo a literatura, para esclarecer a constituição do laço dos indivíduos com a política e os sentidos que eles dão a esse traço de sua identidade. 


\section{pro.posições}

$e$-ISSN 1980-6248

http://dx.doi.org/10.1590/1980-6248-2016-0127

Entrevistadores: Qual foi a influência dos trabalhos de Annick Percheron, que deu início aos estudos de socialização política na França, sobre sua trajetória?

Muxel: Meu encontro com Annick Percheron foi decisivo em meu percurso de jovem pesquisadora. Ela fer. parte da banca de defesa da minha tese, foi nessa ocasião que nos encontramos. Como trabalhávamos com temáticas próximas, ela me convidou para participar de uma pesquisa que visava recolher e estudar histórias politicas de familia. Em minha tese, en já tinha estudado uma história politica de família sobre três gerações. Então, nós trabalbamos juntas, e eu participei de várias pesquisas coordenadas por ela. Infelizmente ela faleceu muito cedo, em 1992. Ela me ensinou muito, notadamente a necessidade de se considerar a socialização política dos indivíduos, em primeiro lugar, como o resultado de uma interação entre indivíduos e sociedade. De uma maneira um pouco provocadora para a época, ela considerava a infância como um tempo da vida no qual a política já tinha seu lugar, mostrando que a socialização política intervinha de modo muito precoce na infância, fixando os primeiros simbolos, os primeiros pontos de referência, as primeiras orientações ideológicas por exemplo, o pertencimento à esquerda ou à direita. Essas identificações politicas elementares se enraízam sobre um terreno afetivo ligado à vivência da criança em sua família. Desde muito cedo, a criança sabe reconhecer e diferenciar as escolhas politica de seus pais. Se ela cresce em uma familia na qual não existe interesse particular pela política, nem muitas discussões sobre esse assunto, nem exemplos de engajamento, esse fraco nivel de politização tem fortes chances de se transmitir e de influenciar, por sua vez, sua vida adulta.

Entrevistadores: Grosso modo, poderíamos dizer que suas pesquisas sobre as relações entre jovens e a política demonstram que há menos desinteresse e apatia dos jovens em relação ao mundo da política, que desconfiança e novas formas de participação. Essa questão é muito importante para nós no Brasil, porque a situação nos parece muito similar: é possível observar entre os jovens brasileiros muita desconfiança e descontentamento com a política tradicional e seus mecanismos, inclusive as eleições. Nesse contexto, os jovens procuram outras formas de participação e intervenção na vida política e na cena pública que, em alguns casos, são ainda difíceis de serem identificadas e analisadas com as "lentes" dos pesquisadores, por sua vez, influenciados pelo estudo das "formas tradicionais" de militância política. Você escreveu que é necessário estabelecer um novo paradigma para compreender o 


\section{pro.posições}

$e$-ISSN 1980-6248

http://dx.doi.org/10.1590/1980-6248-2016-0127

engajamento político entre os jovens e também para compreender como os jovens concebem a política, suas possibilidades e limites. Nós poderíamos dizer que existem características específicas de cada ciclo de vida, no que tange à relação com a política? Ou melhor, a passagem pela juventude exerce um efeito específico sobre o modo como os indivíduos concebem e agem em relação ao mundo da política?

Muxel: Na França, a crise de confiança dos cidadãos em relação às instituições políticas e à classe politica é predominante na sociedade toda: crise de partidos politicos, crise em relação ao voto, abstenções crescentes. Assim, a politica dita institucional se tornou objeto de muita desconfiança na atualidade, principalmente se compararmos com as gerações precedentes, politizadas nos anos $1970 \mathrm{e}$ mesmo 1980. Os jovens entram hoje em contato com a politica em um contexto que mudou muito. Entretanto, esse contexto não concerne somente à juventude: é o conjunto da sociedade francesa que desconfia da política. No CEVIPOF (Centre de Recherches Politiques de Sciences Po), nós fazemos há vários anos um barômetro da confiança política, para medir, a cada ano, o estado das relações entre os franceses e as instituições políticas. Atualmente mais de seis em dezfranceses dizerem que eles não têm confiança nem na direita nem na esquerda para governar o país - esse é o resultado tanto entre os jovens quanto entre os menos jovens. Essa crise de mediações políticas é sentida por todas as gerações, mas ela provoca entre os jovens alguma coisa um pouco diferente, porque, para as outras gerações, o modelo de socialização política fixou alguns pontos de referência, certos fundamentos e comportamentos, sobretudo em relação ao voto. Nesse sentido, os jovens são ainda mais atingidos pela tentação da abstenção que os mais velhos; eles têm também a tendência a desenvolver uma relação mais protestatória em relação à política e a reivindicar que ela tenha mais legitimidade. Pode-se, assim, observar um novo paradigma de cidadania, cujos princípios são desconfiança, intermitência do voto e ações protestatórias. O protesto não é somente um elemento da cultura política da esquerda, essa prática adquiriu legitimidade em todas as camadas da sociedade, independentemente de quais sejam suas afiliações políticas, incluindo a cultura política de direita. Os comportamentos da direita, no entanto, refletem mais intensamente essas transformações, reforçando seus traços; os cidadãos identificados com a direita são ainda mais desconfiados, abstencionistas e têm, além disso, uma postura protestatória.

No barômetro da confiança política do CEVIPOF, nós fižemos a seguinte questão: "Seria melhor ter um homem forte, que não precisasse se ocupar nem de eleições nem do Parlamento para governar o país? " e 50\% dos franceses responderam afirmativamente a essa 


\section{pro.posições}

$e$-ISSN 1980-6248

http://dx.doi.org/10.1590/1980-6248-2016-0127

questão. Na França, a situação política atual é bastante paradoxal. Encontram-se desde cidadãos que demandam autoridade, verticalidade, lideranças fortes, até cidadãos favoráveis à democracia direta, que querem ampliar a democracia participativa e não querem mais se submeter às mediaçoes politicas e institucionais da representação democrática. Nesse sentido, a França é atualmente um país difícil para se governar, porque, para reabilitar a confiança institucional, a classe politica deve integrar demandas contraditórias oriundas dos cidadãos. A ascensão do populismo na Europa, com destaque para a rejeição da imigração e a preferência pelas questões centradas na situação nacional, privilegiando os cidadãos franceses em relação aos estrangeiros nas políticas públicas, expressam esse mal-estar da população e o desenvolvimento das forças antipoliticas. Na França, é preocupante que uma parte significativa da juventude, cerca de um terço, se prepara para votar em Marine Le Pen no primeiro turno da eleição presidencial de 2017.

A esses fatores conjunturais vêm se combinar fatores estruturais ligados ao tempo da juventude, que não é um periodo da vida como qualquer outro. A juventude é um tempo de transição na constituição da identidade política dos indivíduos. Eu desenvolvi a noção de "moratória política dos anos de juventude", no sentido de que se trata de um periodo em que alguma coisa está se construindo, se fabricando, mas não está ainda finalizada. É por essa raz̃ão que os jovens são mais inconstantes em sua participação eleitoral e em suas escolhas de voto. O mesmo ocorre em relação às formas de expressão e de participação política que eles podem adotar: se eles participam de manifestaçoes e mobilizações coletivas, se se engajam em associações para defender certas causas políticas, tais engajamentos são frequentemente esporádicos e pouco duráveis. Os jovens tendem a facilmente se desengajar e se retirar do combate que, entretanto, eles mesmos haviam escolbido conduzir. Portanto, é um momento da vida no qual vão se fixar as convicções, as escolhas, os comportamentos, mas em um periodo ainda de grande mobilidade, fluidez e flexibilidade da própria identidade politica. É um periodo muito interessante para ser estudado, porque ele coloca em tensão muitas questões individuais e coletivas, e também muito paradoxos, ambivalências, até mesmo contradições. É, verdadeiramente, um tempo específico no processo da socialização política, com todos seus riscos e seus rearranjos constantes. Um tempo também no qual existe, sem dúvida alguma, uma disponibilidade talvez. mais acentuada à rebelião. E podemos dizer, pelo menos, que há uma energia, nessa idade da vida, que facilita a passagem à ação; e os engajamentos, mesmo que provisórios estarão mais predispostos à radicalidade política, em comparação a outras idades da vida. São, portanto, esses fatores conjunturais e estruturais que se misturam na relação da juventude com a cidadania. Os jovens não são despolitizados, eles não 


\section{pro.posições}

$e$-ISSN 1980-6248

http://dx.doi.org/10.1590/1980-6248-2016-0127

se afastaram da ação coletiva. É preciso estar atento aos modos como os jovens recompõem sua relação com a política. A individualização do processo de formação da identidade não exclui sua implicaşão no coletivo.

Entrevistadores: Gostaríamos de lhe fazer duas perguntas sobre o comportamento dos jovens em relação à democracia, sobretudo dos jovens mais pobres e vulneráveis, seja no sistema escolar, seja no mercado de trabalho. Por que os jovens que estão em uma situação de vulnerabilidade econômica e social não se sentem mais facilmente atraídos por discursos ou instituições/entidades/movimentos de caráter classista? Além disso, o modo como os jovens têm questionado o funcionamento da democracia representativa - rejeitando determinados elementos desse sistema, como os partidos políticos e mesmo as eleições, rejeitando algumas vezes até mesmo dialogar com instâncias do Estado - pode representar um risco para as democracias consolidadas e para aquelas que ainda estão se consolidando, ou isso poderia fazer avançar esses regimes democráticos?

Muxel: Sua questão é legítima, mas não há uma resposta simples para ela. A crise das mediações tradicionais da política é o fruto de um longo processo bistórico que condurizu a uma experiência necessariamente desencantada e crítica da democracia. A democracia suscita muitas esperanças, mas também decep̧̧̃es à altura das expectativas. Myriam Revault d'Allones e Claude Lefort mostraram bem que a democracia é um projeto ambicioso - pluralidade de opiniões e governança a partir dessa pluralidade -, que acaba terminando por decepcionar as expectativas dos cidadãos, que se tornam cada vez mais exigentes. O processo de individualização da relação com a política também toma parte desse movimento enganoso. Hoje os indivíduos têm laşos bem mais distendidos com seus grupos de pertencimento, podendo fixar novas identidades coletivas. Isso é verdadeiro para quaisquer instituicões, seja na relação entre professores e alunos, seja nas relações no seio da família, nas relações de um casal ou ainda nas relaçoes de trabalho. Nessa conjuntura, é cada vez mais demandada dos indivíduos a definição de suas próprias ações, suas próprias escolhas e seus próprios comportamentos. Em um contexto de crise das religiōes, crise de crenças, crise de afiliaçoos políticas e ideológicas, os indivíduos são libertados das tutelas organizacionais, prescritoras de atitudes, de opiniões e comportamentos, e devem produąir as escolhas e as ações de formas mais autônomas. Essa conjunção - de uma parte, uma crise de instituições e de mediações; de outra, a individualização da socialização - conduz a uma 


\section{pro.posições}

$e$-ISSN 1980-6248

http://dx.doi.org/10.1590/1980-6248-2016-0127

perda de fé no coletivo institucionalizado. Em contrapartida, outras vias de participação em coletivos autônomos e não institucionais são procuradas pelos indivíduos, vias que sejam mais imprevisiveis, mais contratuais e menos duráveis. Eu não faço parte dos "declinistas" que sustentam a ideia de uma apatia civica, notadamente entre as jovens gerações. Eu penso, ao contrário, que as formas atuais de politização dos indivíduos marcam um momento novo da nossa bistória democrática, no qual se tenta articular o conjunto de questionamentos das mediações tradicionais da política, a demanda pela democracia direta e pela participação ativa dos cidadãos. Mas não podemos excluir o fato de que a desconfiança generalizada a respeito das instituições pode também desembocar em uma demanda de autoridade significativa e visivel em certos segmentos da população. Certos movimentos extremistas ou certos partidos "fora do sistema" podem se alimentar da sobrevalorização da ordem. É o caso de muitos partidos populistas na Europa, atualmente. Na França, o Front National cristaliza a necessidade de radicalização dos jovens que procuram uma alternativa em relação aos grandes partidos, percebidos tão somente como receptáculos das elites. Outras formas de radicalizaçãa política existem também na extrema esquerda. A religião pode também ser um vetor do extremismo político. $O$ jïhadismo que vemos operar na Europa e a utilizạąão da violência terrorista mais extrema colocam em questão a própria existência da democracia. As formas de radicalização política que observamos não são marcadas necessariamente pela passagem a atos violentos, mas elas respondem a uma demanda de sentidos diante da crise das instituições. Novos coletivos de pertencimento são buscados. Se a grande maioria dos jovens se apresenta como cidadãos críticos, mas ligados aos fundamentos e aos princípios democráticos, utilizando uma ampla paleta de instrumentos de expressão, do voto à manifestação, uma infima minoria pode se fazer ouvir por meio do uso da violência política, procurando o caos e o questionamento dos regimes democráticos. Há uma certa urgência em nossas sociedades para se reencontrar o caminho de uma adesão política que reabilite a confiança na ação pública dos eleitos e dos governantes e, portanto, na democracia representativa.

Entrevistadores: Gostaríamos ainda de lhe perguntar sobre o papel da família que, parece-nos, guarda ainda uma função bastante importante nos processos de socialização e também de socialização política. Assim, gostaríamos de ouvi-la falar sobre o papel da família na socialização das novas gerações e também sobre seus estudos que discutem as relações entre afetividade e política, entre o engajamento político e os afetos. 


\section{pro.posições}

http://dx.doi.org/10.1590/1980-6248-2016-0127

\section{$e$-ISSN 1980-6248}

Muxel: Em meus últimos trabalhos, estudei o que chamei a "politização intima" dos individuos. Os sociólogos das famílias, notadamente François de Singly, insistem sobre o fato de que a família é cada vez mais relacional, individualizada, e que ela é vivida cada vez. menos como uma instância coletiva. Isso tem um impacto sobre a socialização política familiar, mas a família continua a ter um papel importante por meio dos afetos, através do lugar que ela ocupa para os indivíduos em um mundo globalizado, cada vez. mais complexo de se compreender e no qual as mensagens são cada vez, mais dificeis de descriptografar. Nesse contexto, a família tem um papel de filtro, permitindo a decodificação de certos pontos de referência elementares e essenciais na constituição das identidades politicas de crianças e adolescentes. Mas a família, cada vez. mais, está em uma situação de concorrência com outras instâncias de socialização, notadamente a internet, as redes sociais, as mídias e todos os meios de informação e comunicação. A familia é sempre uma referência, é sempre na família que os indivíduos dizem ter mais confiança. Nas representações sociais, a instituição familiar continua a ser um polo protetor, um polo de referência, um polo afetivo importante. Na França, a filiação política dos indivíduos, majoritariamente, se aproxima das escolhas politicas de seus pais. Dois terços dos franceses declaram ter as mesmas escolhas e as mesmas orientações politicas de seus pais. Portanto, apesar do caos, apesar da individualização que evoquei anteriormente, apesar da crise de afiliações politicas e partidárias no nivel institucional, a continuidade intergeracional das orientações ideológicas dos indivíduos, que opera pelo filtro afetivo familiar, atinge a maioria dos indivíduos. E nesse processo de transmissão as mulheres e as mães têm um papel mais importante que os pais.

Entrevistadores: Ainda sobre a influência dos pais sobre a posição política dos filhos, poderíamos dizer que, em um sentido contrário, os pais militantes ou muito engajados em questões políticas tendem a ter filhos que recusam a política?

Muxel: Os filhos de militantes podem sofrer com a falta de disponibilidade de seus pais e, portanto, rejeitar a política. Mas constata-se que os militantes, os dirigentes sindicais e os homens politicos tiveram, em sua maioria, pais que eram também militantes. O militantismo também se transmite. 


\section{pro.posıções \\ $e$-ISSN 1980-6248}

\section{Referências}

Muxel, A. (2001a). Les jeunes d'Europe du Sud et la politique. Une enquête comparative

France, Italie, Espagne (Codirection Marlaine Cacouault). Paris: L’Harmattan.

Muxel, A. (2001b). L’expérience politique des jeunes. Paris: Presses de Sciences Po.

Muxel, A. (2002, octobre-décembre). La participation politique des jeunes: soubresauts, fractures, ajustements. Revue Française de Science Politique, 52(5-6), 521-544.

Muxel, A. (2003). Le vote de tous les refus. Les élections présidentielles et législatives de 2002. Paris: Presses de Sciences Po.

Muxel, A. (2005). Les jeunes et les élections européennes : un paradoxe démocratique?. In

P. Delwit, \& Ph. Poirier, Parlement puissant, électeurs absents? Les élections européennes de juin 2004. Brussels: Editions de l'Université de Bruxelles.

Muxel, A. (2008, octobre). Toi, moi et la politique. Amour et convictions. Paris: Éditions du Seuil.

Submetido à avaliação em 25 de agosto de 2016, revisado em 06 de dezembro de 2016, aceito para publicação em 06 de março de 2017. 